\title{
Plant uptake of Carbon-14 released from underground disposal of radioactive waste
}

\author{
F. van Dorp and M.S. Brennwald
}

NAGRA, Hardstrasse 73, 5430 Wettingen, Switzerland

\begin{abstract}
Radiocarbon (C-14) is potentially important in radioactive waste. Because the carbon transfer through the biosphere is principally different from the transfer of other radionuclides, using an empiric soil-to-plant transfer coefficient (also called soil/plant concentration ratio) in the same way as with other nuclides is inappropriate and can lead to wrong results in biosphere assessment models. C-14 concentrations and fluxes in the biosphere are strongly influenced by the concentrations and fluxes of stable carbon. We developed a new process-based model of the soil to plant transfer of C-14 for the use in the safety assessments of radioactive waste repositories. The model describes the steady-state nuclide abundance in the plants due to the fluxes of water and solid matter within the biosphere system. To study the model sensitivity to parameter variations, parameter variations were studied. We found that the carbon cycle plant $=>$ soil $=>$ canopy determines the uptake of $\mathrm{C}-14$ by crops. The major parameters are the plant productivity (yield) and the exchange rate of carbon between the air within the canopy and the general atmosphere. The quantification of this exchange rate of carbon is, however, a major open issue.
\end{abstract}

\section{INTRODUCTION}

Radiocarbon (C-14) is potentially important in radioactive waste. $\mathrm{C}-14$ concentrations and fluxes in the biosphere are strongly influenced by the concentrations and fluxes of stable carbon. The carbon transfer through the biosphere is, therefore, principally different from the transfer of other radionuclides. Hence, using an empiric soil-to-plant transfer coefficient (also called soil/plant concentration ratio) to model radionuclide uptake from the soil in the same way as for other nuclides may, therefore, lead to overly pessimistic results in biosphere assessment models.

\section{MODEL DESCRIPTION}

We developed a new process-based model of the soil-to-plant transfer of C-14 for the use in the safety assessments of radioactive waste repositories. The new model is based on Klos et al. 1996 and describes the steady-state nuclide abundance in the plants due to the fluxes of water and solid matter within the biosphere system (see Figure 1), which is reflected by several compartments: (1) biosphere aquifer, (2) deep soil matrix, (3) top soil matrix, (4) soil gas, (5) atmosphere within the plant canopy, (6) above-ground plant, (7) roots and (8) organic matter in the soil. Top soil, deep soil and aquifer contain calcium carbonate. We assumed that groundwater containing $\mathrm{C}-14$ is used for irrigation and the C-14 is transferred to the soil. Endpoints of the model calculations are C-14 concentrations and specific activities in the different compartments. Input data were the same as for previous assessments (Nagra, 2002).

To study the model sensitivity to parameter variations, the following parameter variations were studied (Figure 2): (1) exchange rate between the air within the canopy and the general atmosphere, (2) crop production rate, (3) uptake of carbon by the roots (often assumed to correspond to 1-2\% of the carbon in the plant), (4) release of the C-14 from the irrigation water to the air instead of to the soil and transfer of water from the aquifer to the top soil by capillary rise. 


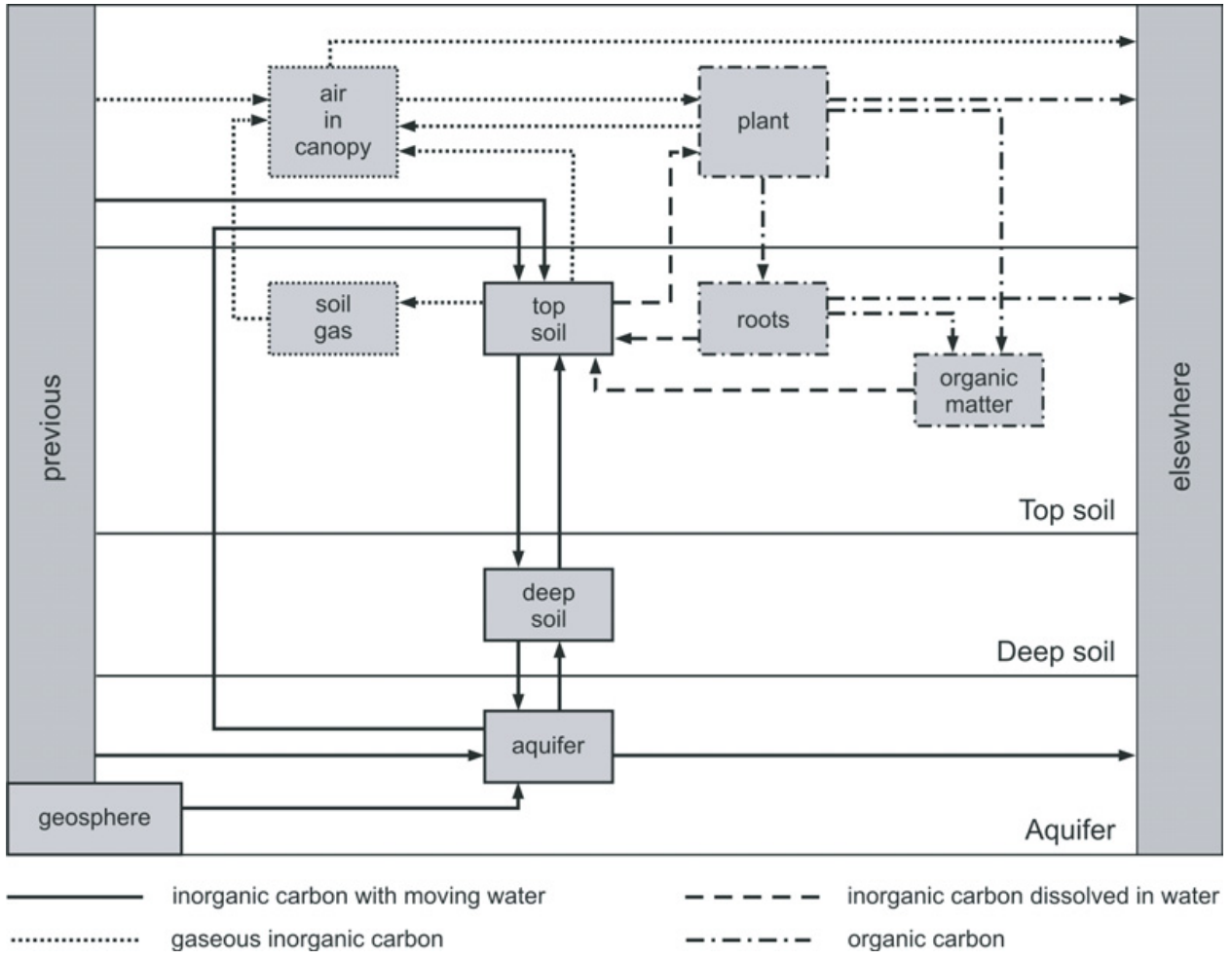

Figure 1. Conceptual biosphere model for the steady-state cycling of radiocarbon.

\section{RESULTS AND DISCUSSION}

We found that the carbon cycle plant $\Rightarrow>$ soil $\Rightarrow$ canopy determines the uptake of C-14 by crops. The major parameters are the exchange rate of carbon between the air within the canopy and the general atmosphere and the plant productivity (yield) (Figure 2). The quantification of this exchange rate of carbon is, however, a major open issue. In general, this exchange rate will be large when plant density is low, i.e. in the beginning of the growing season. The exchange rate will become lower when the canopy is being closed. This is also when the highest photosynthesis rates occur, which determines the specific activity of the harvested product. For high exchange rates the soil/plant concentration-ratio concept with a contribution of direct uptake by the roots from the soil of $2 \%$ of the total carbon in the plant will result in higher specific activities in the crop than the proposed specific activity model. At low exchange rates new model will lead to significantly higher calculated specific activities of C-14 in the crop.

\section{References}

[1] Klos R.A., Müller-Lemans H., Van Dorp F., Gribi, P., 1996 TAME: the Terrestrial-Aquatic Model of the Environment: model definition. Nagra Technical Report NTB 93-04. Nagra, Wettingen, 1996.

[2] Nagra, 2002. National Cooperative for the Disposal of Radioactive Waste: Project Opalinus Clay: Safety Report: Demonstration of disposal feasibility for spent fuel, vitrified high-level waste and long-lived intermediate-level waste (Entsorgungsnachweis). Nagra Technical Report 02-05. Nagra, Wettingen, 2002. 

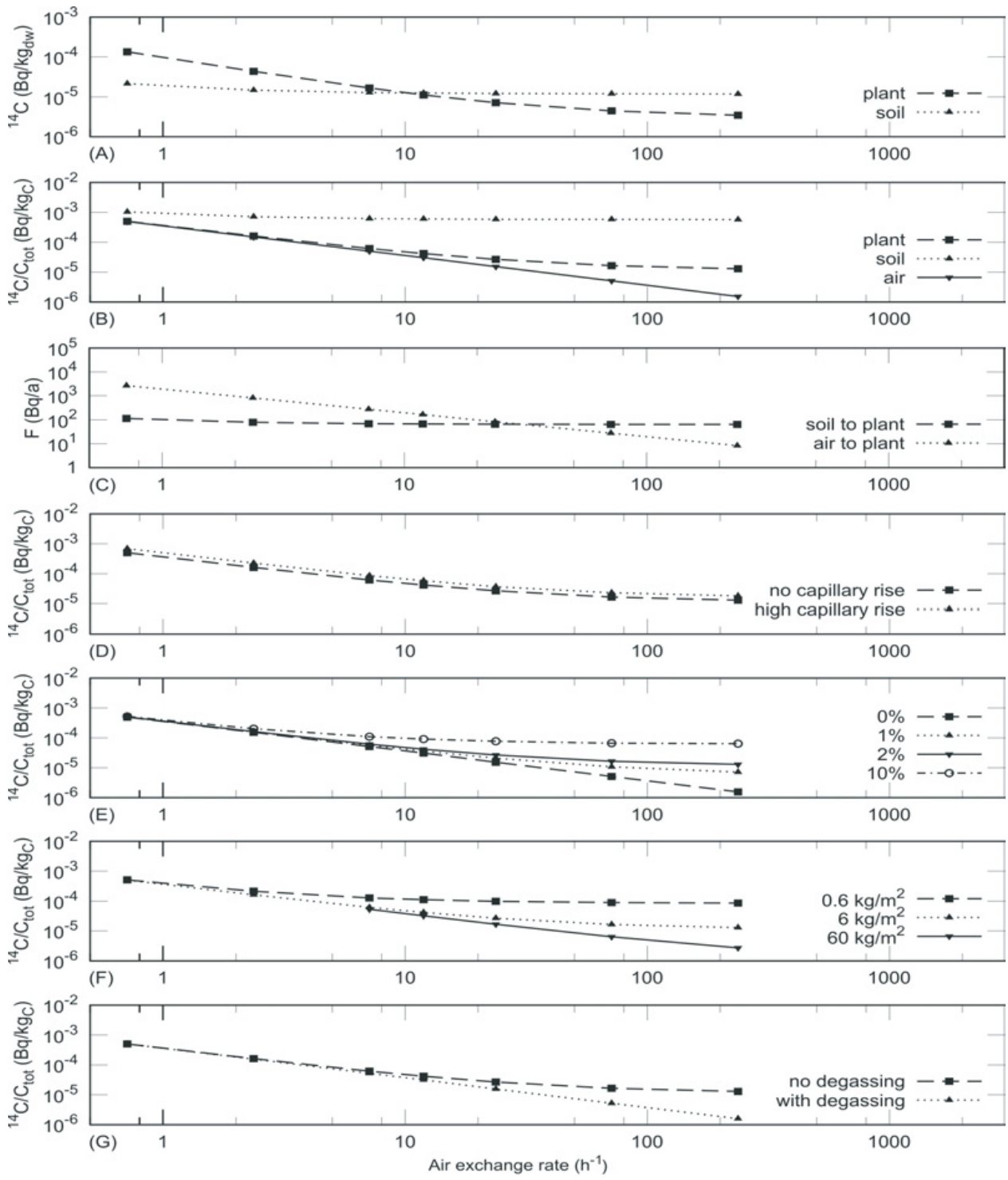

Figure 2. Results of the radiocarbon model as function of the air exchange rate: carbon concentration in top soil and plant (A); specific activity in plant soil and air (B); carbon fluxes from soil and air to plant (C); specific activity for different rates of capillary rise (D), specific activity for different contributions of C-14 by root uptake from soil (E), specific activity for different plant production rates (F) and specific activity when assuming no degassing or degassing of the irrigation water $(\mathrm{G})$. 
